\title{
Pterygium and ultraviolet radiation: a positive correlation
}

\author{
DAVID J. MORAN AND FRED C. HOLLLOWS \\ From the Department of Ophthalmology, Prince of Wales Hospital, High Street, Randwick, \\ New South Wales 2031, Australia
}

SUmmary Pterygium has long been believed to be an environmental disease, Ultraviolet (UV) radiation playing a major role in its development. In examination of more than 100000 Aborigines and non-Aborigines in rural Australia a strong positive correlation between climatic UV radiation and pterygium prevalence was found, providing further evidence of a causal relationship. In addition interesting differences were found in prevalence in the different racial groups and between the sexes. These differences may be explained by differences in lifestyle.

The idea that sunlight itself may be a major risk factor in certain eye diseases is becoming increasingly widely accepted, and pterygium has long been believed to be among these. In particular, Cameron ${ }^{1}$ considered the global pattern of pterygium and related it through latitude to ultraviolet (UV) radiation. An excellent recent report by Taylor ${ }^{2}$ reviewed the theories of pathogenesis of pterygium and provided supporting evidence implicating UV radiation, presenting a small subset of the subjects of this study.

The examination of more than 64000 Aborigines and 40000 non-Aborigines throughout rural Australia provided an opportunity to assess point prevalence for pterygium in large groups of people in different climatic zones of this arid continent. Except for limited regions of its coast, especially the eastern seaboard, and of its lower tropical altitudes in the monsoon season, Australia is subject to the prolonged influence of the sun burning in mostly cloudless skies. Most of the land mass averages 9 or 10 hours of sunshine a day for the year, while only the extreme eastern and southern regions of the continent have 7 hours or less mean daily sunshine. Fig. 1 shows the pattern of erythemal UV radiation levels in Australia. $^{3}$

Aboriginal Australians form a significant proportion of the population of the more arid parts of the country, and their communities are widely distributed either throughout their tribal homelands or as fringe settlements near white townships or cattle stations. Their living conditions are such that they inevitably

Correspondence to Dr Moran. spend the greater part of their lives outdoors. Most communities have, at best, makeshift housing in surroundings of bare ground and have the sorts of health problems which invariably occur in dispossessed peoples.

White Australians, however, enjoy a high standard of living in all parts of Australia and are practically always well housed. They are also most usually in indoor occupations except for pastoral and agricultural workers.

\section{Materials and methods}

Data for this study were gathered by ophthalmologist's of the National Trachoma and Eye Health Program who examined the 64314 Aborigines and 40799 nonAborigines for eye disease during a period of 3 years' field work. An attempt was made to obtain thorough coverage of the Aboriginal population, and in all just over $50 \%$ of an estimated population of 127000 was seen in the areas visited by the teams.

The non-Aboriginal population was to a certain extent self selected, and no attempt was made to obtain a comprehensive coverage. Because of the limited resources available to the clinical teams it was possible in some larger rural centres to see only those non-Aborigines who wished to attend the clinics with a specific complaint or for a check-up. NonAboriginal school children, however, were screened in large numbers, and the number of adults attending clinics for a check-up was greater proportionally than in urban eye clinics.

A detailed account of the methods of sampling, 
Fig. 1 Map of Australia showing ultraviolet zones (derived from mean distribution of daily total erythemal $U V$ dose when cloud cover is taken into account).

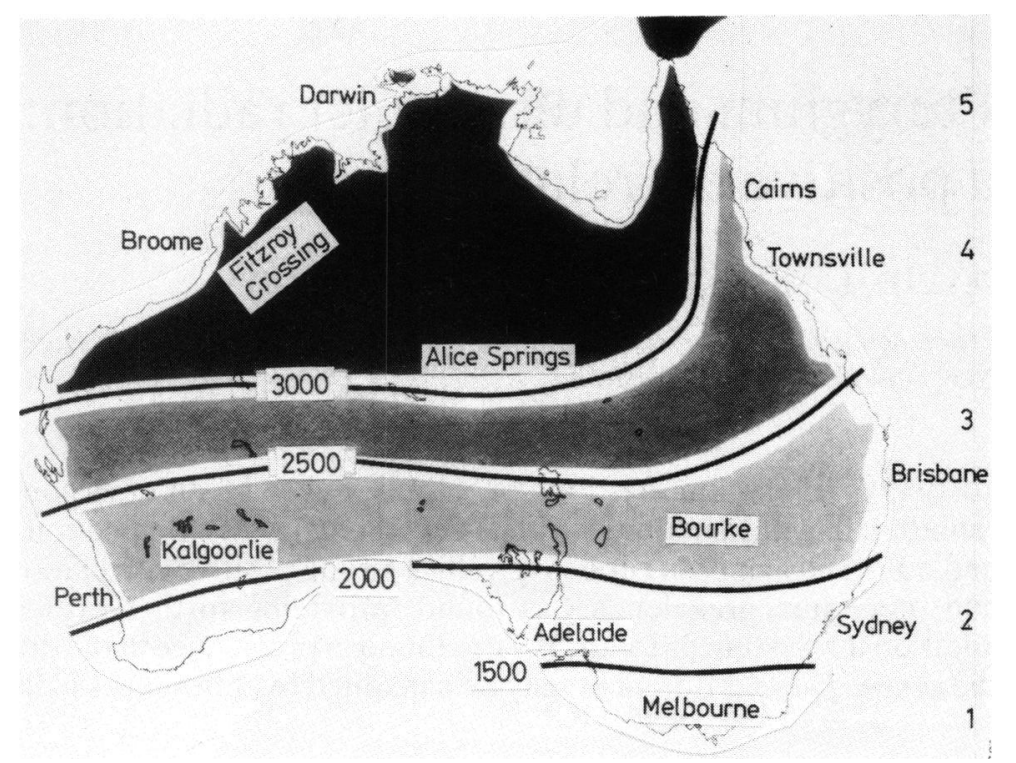

diagnostic criteria, and data handling has been published. ${ }^{4}$ For the purpose of this presentation the diagnosis of pterygium was made if one or more of the typical wing shaped conjunctival lesions extending on to the cornea was present in either eye.

For climatic analysis the mainland of Australia was divided into 5 zones according to the levels of UV radiation in erythemal units (Fig. 1). Erythemal units are arbitrary units defined as the integral of the global solar flux density curve in the ultraviolet spectrum continuously multiplied by a standard skin erythemal response function. They are thus a calculable measure of biological response to any pattern of the solar UV spectrum.

The $\chi^{2}$ test for statistical significance was used. For convenience only $p$ values are shown.

\section{Results}

The prevalence of pterygium is higher for Aborigines than for non-Aborigines for all ages, and the overall prevalence, $3 \cdot 4 \%$ (2194 of 64314 ), for Aborigines is just over 3 times that for non-Aborigines, $1 \cdot 1 \%$ (442 of 40799 non-Aborigines). Only non-Aboriginal males of working age or older approach the prevalence of their Aboriginal counterparts.

For Aborigines there is no significant difference in prevalence between the sexes for any age group or overall. For non-Aborigines, however, the prevalence in women of $0.65 \%$ remains more or less half that of men, $1.5 \%$, and this holds true for all age groups except 0-19 years, where the difference is more marked and is statistically significant (Table 1, Fig. 2).

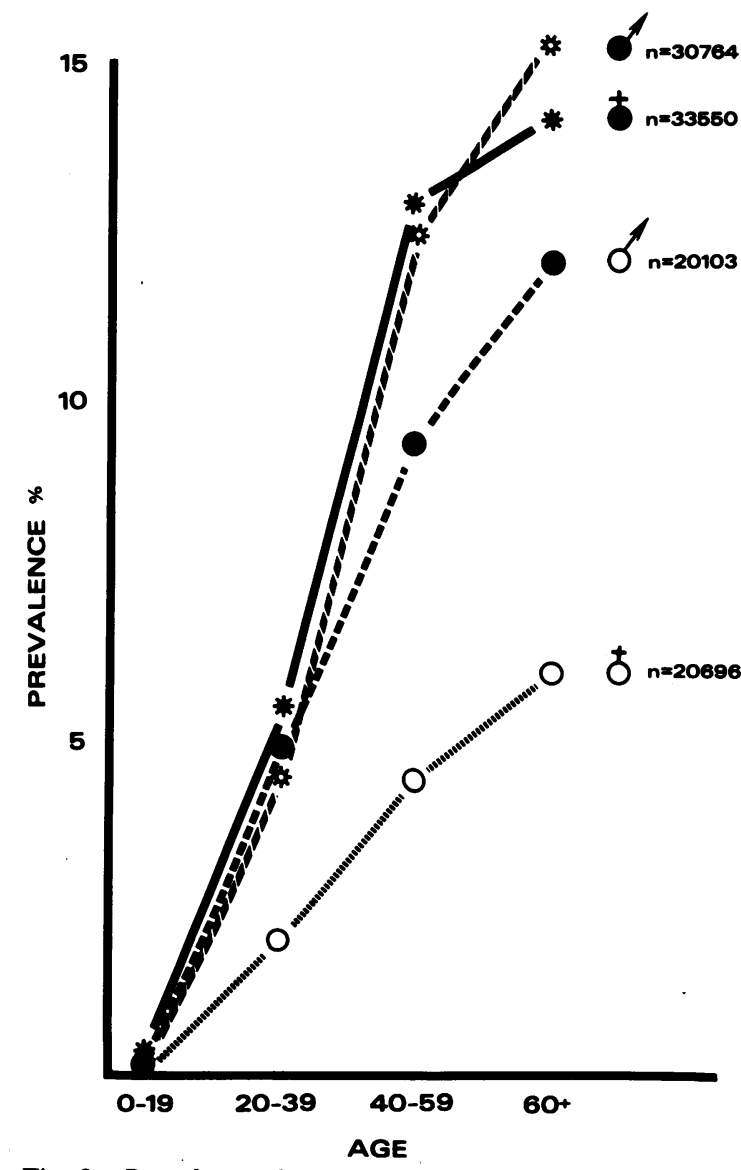

Fig. 2 Prevalence of pterygium against age by race and sex. 
Table 1 Prevalence of pterygium in male and female Aborigines and non-Aborigines by age

\begin{tabular}{|c|c|c|c|c|c|}
\hline & \multirow[t]{2}{*}{ Sex } & \multicolumn{4}{|l|}{ Age } \\
\hline & & $0-19$ & $20-39$ & $40-59$ & $60+$. \\
\hline Aborigines & $\begin{array}{l}\mathbf{M} \\
\mathbf{F}\end{array}$ & $\begin{array}{l}0 \cdot 34 \% \\
n=20402 \\
0 \cdot 25 \% \\
n=21097\end{array}$ & $\begin{array}{l}5 \cdot 5 \% \\
n=4984 \\
4 \cdot 5 \% \\
n=6738\end{array}$ & $\begin{array}{l}12 \cdot 9 \% \\
n=3337 \\
12 \cdot 5 \% \\
n=3568\end{array}$ & $\begin{array}{l}14 \cdot 2 \% \\
n=2041 \\
15 \cdot 3 \% \\
n=2147\end{array}$ \\
\hline Non-Aborigines & $\begin{array}{l}\mathbf{M} \\
\mathbf{F}\end{array}$ & $\begin{array}{l}0 \cdot 16 \% \\
n=16275 \\
0 \cdot 04 \% \\
n=16607\end{array}$ & $\begin{array}{l}4 \cdot 9 \% \\
n=2148 \\
2 \cdot 1 \% \\
n=2563\end{array}$ & $\begin{array}{c}9.9 \% \\
n=1162 \\
4.4 \% \\
n=1086\end{array}$ & $\begin{array}{r}12 \cdot 0 \% \\
n=518 \\
6 \cdot 1 \% \\
n=440\end{array}$ \\
\hline
\end{tabular}

Table 2 Pterygium in Aborigines by UV zone and age

\begin{tabular}{|c|c|c|c|c|c|}
\hline \multirow[t]{2}{*}{ UV zone } & \multirow[t]{2}{*}{ Overall } & \multicolumn{4}{|l|}{ Age } \\
\hline & & $0-19$ & $20-39$ & $40-59$ & $60+$ \\
\hline 1 & $\begin{array}{l}1.6 \% \\
n=509\end{array}$ & $\begin{array}{l}0 \% \\
n=290\end{array}$ & $\begin{array}{l}2 \cdot 2 \% \\
n=139\end{array}$ & $\begin{array}{l}6.9 \% \\
n=58\end{array}$ & $\begin{array}{l}4 \cdot 5 \% \\
n=22\end{array}$ \\
\hline 2 & $\begin{array}{l}2 \cdot 7 \% \\
n=4331\end{array}$ & $\begin{array}{l}0 \cdot 3 \% \\
n=2944\end{array}$ & $\begin{array}{l}5.0 \% \\
n=818\end{array}$ & $\begin{array}{l}11 \cdot 7 \% \\
n=420\end{array}$ & $\begin{array}{l}12 \cdot 1 \% \\
n=149\end{array}$ \\
\hline 3 & $\begin{array}{l}2 \cdot 7 \% \\
n=13867\end{array}$ & $\begin{array}{l}0 \cdot 2 \% \\
n=9668\end{array}$ & $\begin{array}{l}5 \cdot 1 \% \\
n=2241\end{array}$ & $\begin{array}{l}11 \cdot 8 \% \\
n=1342\end{array}$ & $\begin{array}{l}14 \cdot 3 \% \\
n=616\end{array}$ \\
\hline 4 & $\begin{array}{l}3 \cdot 0 \% \\
n=13319\end{array}$ & $\begin{array}{l}0 \cdot 3 \% \\
n=9040\end{array}$ & $\begin{array}{l}4 \cdot 4 \% \\
n=2158\end{array}$ & $\begin{array}{l}12.5 \% \\
n=1412\end{array}$ & $\begin{array}{l}14 \cdot 0 \% \\
n=709\end{array}$ \\
\hline 5 & $\begin{array}{l}4 \cdot 0 \% \\
n=32288\end{array}$ & $\begin{array}{l}0.4 \% \\
n=19557\end{array}$ & $\begin{array}{l}5 \cdot 0 \% \\
n=6366\end{array}$ & $\begin{array}{l}13 \cdot 3 \% \\
n=3673\end{array}$ & $\begin{array}{l}15 \cdot 2 \% \\
n=2692\end{array}$ \\
\hline
\end{tabular}

Table 3 Pterygium in non-Aborigines by UV zone and age

\begin{tabular}{|c|c|c|c|c|c|}
\hline \multirow[t]{2}{*}{ UV zone } & \multirow[t]{2}{*}{ Overall } & \multicolumn{4}{|l|}{ Age } \\
\hline & & $0-19$ & $20-39$ & $40-59$ & $60+$ \\
\hline 1 & $\begin{array}{l}0 \cdot 1 \% \\
n=637\end{array}$ & $\begin{array}{l}0 \% \\
n=317\end{array}$ & $\begin{array}{l}0 \% \\
n=302\end{array}$ & $\begin{array}{l}0 \% \\
n=12\end{array}$ & $\begin{array}{l}16 \cdot 6 \% \\
n=6\end{array}$ \\
\hline 2 & $\begin{array}{l}0.5 \% \\
n=3881\end{array}$ & $\begin{array}{l}0 \% \\
n=3443\end{array}$ & $\begin{array}{l}2 \cdot 7 \% \\
n=224\end{array}$ & $\begin{array}{l}6 \cdot 9 \% \\
n=144\end{array}$ & $\begin{array}{l}5 \cdot 7 \% \\
n=70\end{array}$ \\
\hline 3 & $\begin{array}{l}1 \cdot 0 \% \\
n=14468\end{array}$ & $\begin{array}{l}0 \cdot 1 \% \\
n=12144\end{array}$ & $\begin{array}{l}3 \cdot 3 \% \\
n=1113\end{array}$ & $\begin{array}{l}8 \cdot 3 \% \\
n=793\end{array}$ & $\begin{array}{l}9 \cdot 6 \% \\
n=418\end{array}$ \\
\hline 4 & $\begin{array}{l}1 \cdot 0 \% \\
\mathrm{n}=9651\end{array}$ & $\begin{array}{l}0 \cdot 1 \% \\
\mathrm{n}=8352\end{array}$ & $\begin{array}{l}4 \cdot 7 \% \\
n=768\end{array}$ & $\begin{array}{l}8 \cdot 6 \% \\
n=348\end{array}$ & $\begin{array}{l}12 \cdot 0 \% \\
n=183\end{array}$ \\
\hline 5 & $\begin{array}{l}1 \cdot 4 \% \\
n=12162\end{array}$ & $\begin{array}{l}0 \cdot 1 \% \\
n=8626\end{array}$ & $\begin{array}{l}3.4 \% \\
n=2304\end{array}$ & $\begin{array}{l}6 \cdot 0 \% \\
n=951\end{array}$ & $\begin{array}{l}11 \cdot 4 \% \\
n=281\end{array}$ \\
\hline
\end{tabular}

When the pattern of pterygium prevalence in Aborigines is tested against UV zones, a significant positive correlation emerges $(\mathrm{p}<0.001)$. The lowest prevalence is for the youngest age group $(0 \%$ of 290 $0-19$ year-olds) in the lowest UV intensity zone, and the highest is for the oldest age group (over 60) in the highest UV zone ( $15 \cdot 2 \%$ of 2692 examined). Between these 2 extremes the prevalence shows a substantial increase for increasing age and increasing UV irradiation (Table 2). The trend for non-Aborigines is somewhat similar to that of Aborigines but is much less marked $(p<0 \cdot 05)$, perhaps for reasons discussed below (Table 3 ).

\section{Discussion}

These figures show a strong correlation between climatic UV irradiation and the prevalence of pterygium. Several points need to be made. Firstly, the non-Aboriginal sample is to a certain extent self selected, and this may bias the figures to an unknown degree. Secondly, there is a tendency for a clustering of environmental variables to occur in such a way that the harsher climatic conditions occur in the same regions of the country as the worst standards of housing, hygiene, and nutrition. In our analysis it has not been possible completely to disentangle the environmental variables.

It should also be mentioned that although Aboriginal populations are mobile they do not as a rule move out of the climatic areas in which we examined them, and practically all the Aborigines we examined lived at or near the place of examination.

With these points in mind it is tempting to speculate that differences in lifestyle may explain the different patterns in the race and sex groups. The poor standard of housing which forces Aborigines to spend all their waking hours outdoors causes them to be more exposed to solar radiation than those with good housing. In addition it should be remembered that sitting in the shade or keeping the eyes out of direct sunlight may give but little protection against UV radiation, which is scattered much more by the atmosphere than visible or infrared rays. By the same token areas of poor Aboriginal housing are usually on bare ground, where albedo (reflected light as a proportion of incident light) is highest, thus maximising solar injury.

A combination of these factors may be responsible for the comparable prevalence in male and female Aborigines and the fact that the rates are higher than for non-Aborigines. In rural Australia nonAboriginal women in general spend much less time out of doors than the men and are well housed and able to escape from solar radiation either direct or scattered. The lower prevalence rate for nonAboriginal women may simply reflect their lesser climatic exposure, though it appears that the risk of pterygium is an inevitable accompaniment to life in sunny, arid areas.

It may be unreasonable to advocate the large scale wearing of protective glasses in at-risk populations simply to prevent pterygium, but protective glasses for the at-risk population may also reduce the incidence of cataract, ${ }^{5}$ Labrador keratopathy, and other ocular conditions associated with ultraviolet radiation.

The authors gratefully acknowledge the assistance of Dr David L. Jones, medical statistician, Health Commission of NSW; and of Ms 
Lee Greenaway, Mary Luning, and June Groves who provided secretarial assistance.

The National Trachoma and Eye Health Program was an independent programme of the Royal Australian College of Ophthalmologists, funded and supported by the Commonwealth Department of Health.

\section{References}

1 Cameron ME. Pterygium throughout the world. Springfield: Thomas, 1965.
2 Taylor HR. Climatic droplet keratopathy and pterygium. Aust J Ophthlmol 1981; 9: 199-206.

3 Paltridge GW, Barton IJ. Erythemal ultraviolet radiation distribution over Australia - the calculations, detailed results and input data including frequent analysis of observed Australian cloud cover. Sydney: CSIRO, Division of Atmospheric Physics, Sydney: 1978; Technical Paper no 33.

4 National Trachoma and Eye Health Program. Sydney: Royal Australian College of Ophthalmologists, 1980.

5 Hollows FC, Moran DJ. Cataract - the ultraviolet risk factor. Lancet 1981; ii: 1249. 